Check for updates

Cite this: RSC Adv., 2017, 7, 23279

Received 10th March 2017

Accepted 20th April 2017

DOI: $10.1039 / c 7 r a 02895 d$

rsc.li/rsc-advances

\section{Solvates and polymorphs of rebamipide: preparation, characterization, and physicochemical analysis $\uparrow$}

\author{
Xinnuo Xiong, Qiaohong Du, Xia Zeng, Jiawei He, Hongqin Yang and Hui Li (DD*
}

This study aimed to investigate the solid forms of the peptic ulcer agent rebamipide (RBM). Four RBM solvates, including dimethyl sulfoxide solvate (RBM/DMSO), dichloromethane solvate $\left(\mathrm{RBM} / \mathrm{CH}_{2} \mathrm{Cl}_{2}\right)$, hydrate $\left(\mathrm{RBM} / \mathrm{H}_{2} \mathrm{O}\right)$, and hemiethanol hemihydrate, were prepared via solvent crystallization. Single crystals of RBM/DMSO and RBM/CH $\mathrm{CH}_{2} \mathrm{Cl}_{2}$ were successfully obtained at $4{ }^{\circ} \mathrm{C}$. These solid forms were both monoclinic with the space group $P 2_{1} / c$. Hirshfeld surface and $2 \mathrm{D}$ fingerprint plot analyses indicated that RBM/DMSO and $\mathrm{RBM} / \mathrm{CH}_{2} \mathrm{Cl}_{2}$ showed similarities in hydrogen bonds but exhibited differences in subtle intermolecular interactions. $\mathrm{RBM} / \mathrm{CH}_{2} \mathrm{Cl}_{2}$ transformed into a novel solid form (form 3) after solvent removal and transformed into another solid form (form 4) when heated at $220{ }^{\circ} \mathrm{C}$. $\mathrm{RBM} / \mathrm{H}_{2} \mathrm{O}$ was converted to form 5 after dehydration. Forms 3-5 were RBM polymorphs. The stability results indicated that $\mathrm{RBM} / \mathrm{H}_{2} \mathrm{O}$, form 3, and form 4 showed good stability at $40{ }^{\circ} \mathrm{C}$ and $75 \%$ relative humidity. Furthermore, the three solid forms displayed higher solubility than commercial RBM (form 1) in both water and phosphate buffer solution (PBS). Compared with form 1, RBM/ $\mathrm{H}_{2} \mathrm{O}$ and form 4 showed a comparable and faster dissolution rate in water and PBS, respectively.

\section{Introduction}

Polymorphism is the ability of a compound to crystallize in different forms, such as polymorphs, solvates, hydrates, and cocrystals, and is a common phenomenon with important applications in academic and industrial research. ${ }^{1-3}$ Various solid forms of active pharmaceutical ingredients (APIs) possess significantly different physicochemical properties, including solubility, dissolution rate, stability, and bioavailability. ${ }^{4-7}$ Therefore, medical researchers must select the optimal solid form of APIs to maximize therapeutic benefits. In addition, different polymorphs may be granted individual patent protection, and the commercial interests of a company could be threatened by the discovery of novel polymorphs. ${ }^{8}$ Thus, investigating the polymorphism of APIs is crucial and has practical utility in pharmaceutical research and development.9,10

Solvates, the crystal forms of a compound that differ in the species or stoichiometry of the included solvent molecules, are widely applied in the pharmaceutical industry. ${ }^{\mathbf{1 0}}$ Accidental solvate formation is undesirable during drug processing because of potentially uncontrollable changes in the physicochemical properties of the drug product. ${ }^{11}$ Conversely, solvates

College of Chemical Engineering, Sichuan University, Chengdu, Sichuan, China. E-mail: lihuilab@sina.com; Fax: +86 028 85401207; Tel: +86028 85405149

$\dagger$ Electronic supplementary information (ESI) available. CCDC 1500324 and 1500325. For ESI and crystallographic data in CIF or other electronic format see DOI: $10.1039 / \mathrm{c} 7 \mathrm{ra02895d}$ with pharmaceutically relevant solvents may improve the physicochemical properties of drugs. ${ }^{12}$ The developmental capacity of APIs have been improved with solvates, such as darunavir ethanolate, ${ }^{13}$ indinavir sulfate ethanolate, ${ }^{\mathbf{1 4}}$ acetone solvate of cabazitaxel, ${ }^{15}$ canagliflozin hydrate, ${ }^{16}$ and dimethyl sulfoxide (DMSO) solvate of trametinib. ${ }^{17}$ Moreover, novel modifications that may be unattainable via ordinary crystallization techniques can be formed by the desolvation (dehydration) of solvates (hydrates). ${ }^{\mathbf{1 8 1 9}}$ Thus, investigating the solvates of APIs and corresponding solid forms after desolvation is of great importance.

Rebamipide (RBM) is used to treat gastric ulcers, acute gastritis, exacerbated chronic gastritis, and dry eye. ${ }^{20-22}$ Two polymorphs (forms 1 and 2 ), ${ }^{23}$ one monohydrate, ${ }^{24}$ two cocrystals, ${ }^{25}$ one solvate (methanol solvate), and several salts ${ }^{26}$ of RBM have been reported. In our previous study, we compared the amorphous forms of RBM that were obtained via milling and spray drying. ${ }^{27}$ The existence of RBM polymorphs and solvates, however, has not been systematically investigated.

Thus, this study aimed to conduct a detailed investigation on the solid forms of RBM, including solvates and polymorphs. Four RBM solvates, namely, dimethyl sulfoxide solvate (RBM/ DMSO), dichloromethane solvate $\left(\mathrm{RBM} / \mathrm{CH}_{2} \mathrm{Cl}_{2}\right)$, hydrate $\left(\mathrm{RBM} / \mathrm{H}_{2} \mathrm{O}\right)$, and hemiethanol hemihydrate $\left(\mathrm{RBM} / \mathrm{EtOH} / \mathrm{H}_{2} \mathrm{O}\right)$, were prepared through solvent crystallization. After the single crystals of RBM/DMSO and $\mathrm{RBM} / \mathrm{CH}_{2} \mathrm{Cl}_{2}$ were successfully obtained, their structures were determined via single-crystal X-ray diffraction (SXRD). Hirshfeld surface (HS) and 2D fingerprint 
plot (FP) were applied to analyze the intermolecular interactions of the two solvates. Although $\mathrm{RBM} / \mathrm{H}_{2} \mathrm{O}$ has been previously reported in a Chinese patent, ${ }^{24}$ more detailed investigations were performed in the present study. In addition, the phase transitions of the solvates upon heating were investigated, and three novel polymorphs of RBM (forms 3-5) were obtained in this process. The stability of the solvates and polymorphs was explored. Based on the results, we further investigated the solubility and dissolution rate of $\mathrm{RBM} / \mathrm{H}_{2} \mathrm{O}$, form 3, and form 4, the stable solid forms of RBM.

\section{Experimental}

\subsection{Materials}

RBM (99\% pure) was purchased from YiTai Technology Co., Ltd. (Shanghai, China) and was consistent with form 1 as reported by Jeon and Sohn (Fig. S1 $\dagger$ ). ${ }^{23}$ Ultrapure water (18 M $\Omega$ resistivity from a Millipore system) was used throughout the experiment. DMSO, $\mathrm{CH}_{2} \mathrm{Cl}_{2}$, methanol ( $\mathrm{MeOH}$ ), ethanol (EtOH), and other solvents were of analytical grade and were purchased from Kelong Co., Ltd. (Chengdu, China).

\subsection{Preparation of RBM solvates and polymorphs}

2.2.1. RBM/DMSO. Colorless single crystals of RBM/DMSO suitable for SXRD were obtained by dissolving $1 \mathrm{~g}$ of form 1 in 15 $\mathrm{mL}$ of DMSO in a sealed beaker flask. The solution was left to crystallize at $4{ }^{\circ} \mathrm{C}$.

2.2.2. $\mathbf{R B M} / \mathbf{C H}_{2} \mathbf{C l}_{2} \cdot \mathrm{RBM} / \mathrm{CH}_{2} \mathrm{Cl}_{2}$ was obtained by dissolving $200 \mathrm{mg}$ of form 1 in $150 \mathrm{~mL}$ of $\mathrm{MeOH} / \mathrm{CH}_{2} \mathrm{Cl}_{2}(2: 1 \mathrm{v} / \mathrm{v})$ solvent mixture via ultrasonication. The resulting solution was then slowly evaporated at $4{ }^{\circ} \mathrm{C}$. Finally, colorless single crystals suitable for SXRD were obtained.

2.2.3. $\mathbf{R B M} / \mathrm{H}_{2} \mathrm{O}$. $\mathrm{RBM} / \mathrm{H}_{2} \mathrm{O}$ was also obtained in the binary system of $\mathrm{MeOH}$ and $\mathrm{CH}_{2} \mathrm{Cl}_{2}$. Form 1 (200 mg) was completely dissolved in $150 \mathrm{~mL}$ of $\mathrm{MeOH} / \mathrm{CH}_{2} \mathrm{Cl}_{2}(3: 1 \mathrm{v} / \mathrm{v})$ with heating and stirring at $55{ }^{\circ} \mathrm{C}$. Then, the solution was cooled to room temperature and slowly evaporated under ambient conditions. White globular solids were obtained after approximately 10 days. However, we failed to obtain single crystals suitable for SXRD.

2.2.4. RBM/EtOH/ $\mathbf{H}_{2} \mathbf{O}$. Form $1(200 \mathrm{mg})$ was dissolved in EtOH $(200 \mathrm{~mL})$ by heating and stirring. The resulting solution was filtered through Whatman filter paper and then evaporated under ambient conditions. Colorless crystals of RBM/EtOH/ $\mathrm{H}_{2} \mathrm{O}$ were obtained after approximately one month. Single crystals suitable for SXRD were still not obtained even after a series of crystallization experiments.

2.2.5. Polymorphs. Three polymorphs were obtained via the phase transitions of the solvates upon heating. Form 3 was generated by heating $\mathrm{RBM} / \mathrm{CH}_{2} \mathrm{Cl}_{2}$ at $150{ }^{\circ} \mathrm{C}$. Form 4 was obtained when $\mathrm{RBM} / \mathrm{CH}_{2} \mathrm{Cl}_{2}$ was further heated at $220^{\circ} \mathrm{C}$. Form 5 was obtained by dehydrating $\mathrm{RBM} / \mathrm{H}_{2} \mathrm{O}$ at $150{ }^{\circ} \mathrm{C}$.

\subsection{Analytical methods}

2.3.1. SXRD. Single-crystal data were collected using the Oxford Diffraction Xcalibur Nova system with Mo K $\alpha$ radiation $(\lambda=0.71073 \AA)$. A suitable crystal was selected and held on an
Xcalibur Eos diffractometer. Cell refinement and data reduction were applied using Olex $2,{ }^{28}$ and the structure was solved and refined using SHELX-97. ${ }^{29}$ Hydrogen bond geometries and packing diagrams were determined with mercury. ${ }^{30}$

2.3.2. HS analysis and 2D FP. HS analysis provides unique information on intermolecular interactions in crystal structures based on electron distribution, which is calculated as the sum of spherical atom electron densities. ${ }^{31,32}$ The normalized contact distance $\left(d_{\text {norm }}\right)$ is given by the following equation:

$$
d_{\text {norm }}=\frac{d_{\mathrm{i}}-r_{\mathrm{i}}^{\mathrm{vdW}}}{r_{\mathrm{i}}^{\mathrm{vdW}}}+\frac{d_{\mathrm{e}}-r_{\mathrm{e}}^{\mathrm{vdW}}}{r_{\mathrm{e}}^{\mathrm{vdW}}},
$$

where $d_{\mathrm{i}}$ and $d_{\mathrm{e}}$ represent the distances from the nearest atom interior and exterior to the surface, respectively, and $r^{\mathrm{vdw}}$ is the van der Waals radii of the atoms. ${ }^{33,34}$ The $2 \mathrm{D}$ FP presents arapid quantitative summary in the percentage of each contact, which is constructed based on the $d_{\mathrm{e}}$ and $d_{\mathrm{i}}$ distances. ${ }^{32}$ All calculations were performed using CrystalExplorer. ${ }^{35}$ HS diagrams were generated using standard (high) surface resolution. Solvent molecules were hidden.

2.3.3. Morphology. RBM/DMSO, $\mathrm{RBM} / \mathrm{CH}_{2} \mathrm{Cl}_{2}$, and $\mathrm{RBM} /$ EtOH $/ \mathrm{H}_{2} \mathrm{O}$ crystals were placed in a transparent glass holder and recorded by an optical microscope (CX21, Olympus, Tokyo, Japan) at $40 \times$ magnification. Photomicrographs were captured by a digital camera (DSC-HX-50, Sony, Tokyo, Japan). Given its small crystal size, $\mathrm{RBM} / \mathrm{H}_{2} \mathrm{O}$ was observed using scanning electron microscopy (SEM). The SEM micrograph was obtained using a scanning electron microscope (JSM-7500F, JEOL, Tokyo, Japan) at $15.0 \mathrm{kV}$. An electrically conductive sample was obtained after coating a sample with a thin layer of gold in vacuum prior to examination.

2.3.4. X-ray powder diffraction (XRPD). XRPD data were collected at room temperature using a diffractometer (X'Pert PRO, PANalytical, Holland) with a PIXcel 1D detector and $\mathrm{Cu} \mathrm{K \alpha}$ radiation ( $\lambda=1.5406 \AA$, generator settings: $40 \mathrm{kV}$ and $40 \mathrm{~mA}$ ). Samples were loaded on a rectangular glass sample holder. Diffraction data were collected in the $2 \theta$ range of $4-50^{\circ}$ with a step size of $0.01313^{\circ}$ and a counting time of $30 \mathrm{~ms}$ per step.

2.3.5. Differential scanning calorimetry (DSC) and thermogravimetric analysis (TGA). Thermal transitions were determined with a differential scanning calorimeter (Q2000, TA, New Castle, DE). Samples (3-5 mg) were heated from $30{ }^{\circ} \mathrm{C}$ to $320{ }^{\circ} \mathrm{C}$ at a rate of $10{ }^{\circ} \mathrm{C} \mathrm{min}^{-1}$ under $\mathrm{N}_{2}$ purge $\left(20 \mathrm{~mL} \mathrm{~min}^{-1}\right)$ in sealed aluminum pans. The instrument was calibrated for temperature and heat flow using indium as the standard.

TGA was performed using an analyzer (TG209F1 Iris, NETZSCH, Germany). Samples (5-8 mg) were determined in aluminum crucibles by heating from $30{ }^{\circ} \mathrm{C}$ to $500{ }^{\circ} \mathrm{C}$ at a rate of $10{ }^{\circ} \mathrm{C} \min ^{-1}$ under $\mathrm{N}_{2}$ purging $\left(60 \mathrm{~mL} \mathrm{~min}^{-1}\right)$.

\subsection{Accelerated stability tests}

The stability of RBM solid forms was investigated at $40{ }^{\circ} \mathrm{C}$ and $75 \%$ relative humidity $(\mathrm{RH})$ International Conference on Harmonization conditions for three months. ${ }^{36}$ In this study, $75 \% \mathrm{RH}$ was achieved with saturated sodium chloride solution in a desiccator. ${ }^{37}$ 


\subsection{Solubility and dissolution studies}

Solubility studies were conducted by adding excess amounts of RBM solid forms to $10 \mathrm{~mL}$ of triple distilled water and phosphate buffer solution (PBS, pH 6.8) in Erlenmeyer flasks.

The suspensions were stirred for $72 \mathrm{~h}$ at constant temperature $\left(37^{\circ} \mathrm{C}\right)$ and then were centrifuged at $10000 \mathrm{rpm}$ for $20 \mathrm{~min}$ using a high-speed refrigerated centrifuge (TGL-16M, Xiangyi, China). The supernatant was filtered through a $0.45 \mu \mathrm{m}$ Millipore filter, appropriately diluted, and analyzed using a UV-vis spectrophotometer (TU-1901, Beijing, China) at $327 \mathrm{~nm}$. Solid residues obtained by filtration were analyzed through XRPD. All solubility measurements were performed in triplicate.

Dissolution studies were conducted using the paddle method on a ZRC-8D dissolution tester (Chuangxing, Tianjin, China) at $100 \mathrm{rpm}$ and $37 \pm 0.5^{\circ} \mathrm{C}$. Samples (30 mg) were added to $900 \mathrm{~mL}$ of dissolution media (triple distilled water and pH 6.8 PBS). Aliquots (5 mL) of the sample solutions were withdrawn at 2, 5, 7, $10,15,20,30,45,60,90$, and $120 \mathrm{~min}$, and then an equivalent amount of fresh media were added. The sample solutions were

Table 1 Crystallographic parameters of RBM forms

\begin{tabular}{lll}
\hline Parameters & $\mathrm{RBM} / \mathrm{DMSO}$ & $\mathrm{RBM} / \mathrm{CH}_{2} \mathrm{Cl}_{2}$ \\
Empirical formula & $\mathrm{C}_{23} \mathrm{H}_{27} \mathrm{ClN}_{2} \mathrm{O}_{6} \mathrm{~S}_{2}$ & $\mathrm{C}_{20} \mathrm{H}_{17} \mathrm{Cl}_{3} \mathrm{~N}_{2} \mathrm{O}_{4}$ \\
Formula weight & 527.03 & 455.71 \\
Temperature $(\mathrm{K})$ & $148.00(10)$ & $142.95(10)$ \\
Crystal system & Monoclinic & Monoclinic \\
Space group & $P 2_{1} / c$ & $P 2{ }_{1} / c$ \\
$a(\AA)$ & $8.9468(9)$ & $14.3285(16)$ \\
$b(\AA)$ & $28.971(3)$ & $9.7542(4)$ \\
$c(\AA)$ & $9.8022(11)$ & $21.475(2)$ \\
$\alpha\left(^{\circ}\right)$ & 90.00 & 90.00 \\
$\beta\left({ }^{\circ}\right)$ & $97.029(10)$ & $136.08(2)$ \\
$\gamma\left({ }^{\circ}\right)$ & 90.00 & 90.00 \\
$V\left(\AA^{3}\right)$ & $2521.6(5)$ & $2081.9(3)$ \\
$Z$ & 4 & 4 \\
$\rho_{\text {calc }}(\mathrm{g}$ cm & -3 \\
$\left.\mu(\mathrm{mm})^{-1}\right)$ & 1.388 & 1.454 \\
Crystal size $\left(\mathrm{mm}{ }^{3}\right)$ & 0.358 & 0.470 \\
$F(000)$ & 1104.0 & 936.0 \\
$2 \theta$ for data collection $\left(^{\circ}\right)$ & $0.4 \times 0.3 \times 0.25$ & $0.4 \times 0.35 \times 0.3$ \\
Index ranges & 5.94 to 52.74 & 5.86 to 52.74 \\
& $-11 \leq h \leq 11$, & $-17 \leq h \leq 12$, \\
& $-36 \leq k \leq 36$, & $-12 \leq k \leq 11$, \\
Reflns collected & $-12 \leq l \leq 12$ & $-18 \leq l \leq 26$ \\
Unique reflns $_{\text {Goodness-of-fit on } F^{2}}$ & 9808 & 8491 \\
$R_{1}(I \geq 2(I))$ & 9808 & 8491 \\
$w R_{2}($ all $)$ & 1.049 & 0.912 \\
& 0.0772 & 0.0590 \\
& 0.2210 & 0.1755 \\
& &
\end{tabular}

filtered through a $0.45 \mu \mathrm{m}$ filter and analyzed with a UV-vis spectrophotometer $(327 \mathrm{~nm})$. Each sample was performed in triplicate.

\section{Results and discussion}

\subsection{Characterization of RBM solvates}

3.1.1. Crystal structure analyses. Unambiguous structural characterization is necessary for drug development and to elucidate structure-property relationships. ${ }^{26} \mathrm{SXRD}$ was used to determine the structures of RBM/DMSO and $\mathrm{RBM} / \mathrm{CH}_{2} \mathrm{Cl}_{2}$. The crystallographic data and refinement details of these forms are listed in Table 1 . The hydrogen bonds present in the crystal structures are listed in Table 2 .

$\mathrm{RBM} / \mathrm{DMSO}$ was solved in space group $P 2_{1} / c$. The stoichiometric ratio of the RBM and DMSO molecules was $1: 2$. RBM molecules were connected to each other through $\mathrm{R}_{2}^{2}(8)$ dimer

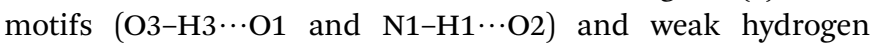
bonds of $\mathrm{C}-\mathrm{H} \cdots \mathrm{Cl}\left(3.734 \AA\right.$, $\left.145^{\circ}\right)$ [Fig. 1(a)]..$^{38}$ One DMSO molecule was connected to RBM molecules through N2-H2 $\cdots$ O6 hydrogen bonds and three weak auxiliary $\mathrm{C}-\mathrm{H} \cdots \mathrm{O} 6$ interactions, while another DMSO molecule contacted with RBM molecules through $\mathrm{C} 20-\mathrm{H} 20 \mathrm{~B} \cdots \mathrm{Cl} 1$ weak interactions [Fig. 1(b)]. RBM molecules were arranged in layers that stretched in a "W" shape along the $a b$ plane. DMSO molecules were located between the layers of RBM molecules [Fig. 1(c)]. In addition, $\pi \cdots \pi$ stacking was observed in the double-layer part of the "W".

$\mathrm{RBM} / \mathrm{CH}_{2} \mathrm{Cl}_{2}$ was solved in space group $P 2_{1} / c$. The stoichiometric ratio of the $\mathrm{RBM}$ and $\mathrm{CH}_{2} \mathrm{Cl}_{2}$ molecules was $1: 1$. $\mathrm{RBM}$ molecules were also connected to each other through $\mathrm{R}_{2}^{2}(8)$ dimer motifs (O4-H4 $\cdots \mathrm{O} 1$ and N1-H1 $\left.\cdots \mathrm{O} 3\right)$ [Fig. 2(a)]. ${ }^{38}$ Each dimer was connected to neighboring molecules through $\mathrm{N} 2-\mathrm{H} 2 \cdots \mathrm{O} 1$ hydrogen bonds and weak $\mathrm{C} 2-\mathrm{H} 2 \mathrm{~A} \cdots \mathrm{O} 4$ hydrogen bonds $\left(3.355 \AA \mathrm{A}^{\circ}\right)$, thus resulting in a sheet-like structure. The sheets were connected to each other through weak $\mathrm{C}-\mathrm{H} \cdots \mathrm{Cl}$ (3.629 $\AA, 138^{\circ}$ ) hydrogen bonds, which were stronger than those in $\mathrm{RBM} / \mathrm{DMSO}$ (Fig. $\mathrm{S} 2 \dagger$ ). $\mathrm{CH}_{2} \mathrm{Cl}_{2}$ molecules interacted with RBM molecules through the weak hydrogen bonds of C20H20B $\cdots \mathrm{O} 2\left(3.146 \AA, 176^{\circ}\right)$ [Fig. 2(b)]. In 2D packing, the molecules were arranged in a corrugated sheet when viewed down the $c$-axis [Fig. 2(c)]. $\pi \cdots \pi$ stacking was observed in the circular part of $\mathrm{RBM} / \mathrm{CH}_{2} \mathrm{Cl}_{2}$ [Fig. 2(d)].

3.1.2. HS analysis and 2D FP. The HSs for RBM/DMSO and $\mathrm{RBM} / \mathrm{CH}_{2} \mathrm{Cl}_{2}$ were mapped over $d_{\text {norm }}$, shape index, and curvedness. The large, deep red, circular depressions in the maps of

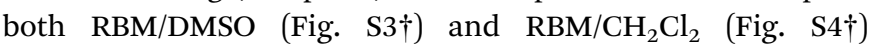

Table 2 Hydrogen bond metrics in crystal structure

\begin{tabular}{llllll}
\hline Crystal form & Interactions & $\mathrm{H} \cdots \mathrm{A}(\AA)$ & $\mathrm{D} \cdots \mathrm{A}(\AA)$ & $<$ DHA $\left({ }^{\circ}\right)$ & Symmetry code \\
\hline RBM/DMSO & $\mathrm{O} 3-\mathrm{H} 3 \cdots \mathrm{O} 1$ & 1.685 & 2.505 & 164.92 & $x, y, z+1$ \\
& $\mathrm{~N} 1-\mathrm{H} 1 \cdots \mathrm{O} 2$ & 2.005 & 2.869 & 166.83 & $x, y, z-1$ \\
& $\mathrm{~N} 2-\mathrm{H} 2 \cdots \mathrm{O} 6$ & 2.097 & 2.890 & 149.64 & $x, y-1, z$ \\
$\mathrm{RBM} / \mathrm{CH}_{2} \mathrm{Cl}_{2}$ & $\mathrm{O} 4-\mathrm{H} 4 \cdots \mathrm{O} 1$ & 1.602 & 2.505 & 172.14 & $x, y+1, z$ \\
& $\mathrm{~N} 1-\mathrm{H} 1 \cdots \mathrm{O} 3$ & 1.940 & 2.821 & 173.33 & $-x+1, y-1 / 2,-z+3 / 2$
\end{tabular}


corresponded to strong $\mathrm{H}$-bonding interactions $(\mathrm{H} \cdots \mathrm{O} / \mathrm{O} \cdots \mathrm{H})$, whereas the small spots were due to $\mathrm{C} \cdots \mathrm{H}, \mathrm{H} \cdots \mathrm{H}$ and $\mathrm{Cl} \cdots \mathrm{H}$ contacts. The bright red hollows that represent concave regions in the shape index map were due to the $\pi \cdots \pi$ interactions of the aromatic rings; moreover, $\pi \cdots \pi$ stacking was evident in the visible large flat area on the curvedness surface. ${ }^{33}$ These results were consistent with the findings obtained in the crystal structure analyses. 2D FPs are useful in comparing the different crystal structures for a given molecule because of their uniqueness for a particular crystal form. ${ }^{32}$ The FPs of RBM/ DMSO and $\mathrm{RBM} / \mathrm{CH}_{2} \mathrm{Cl}_{2}$ displayed significant differences (Fig. 3). The two sharp spikes near $d_{\mathrm{e}}+d_{\mathrm{i}} \approx 1.5 \AA$ in the FPs of $\mathrm{RBM} / \mathrm{DMSO}$ and $\mathrm{RBM} / \mathrm{CH}_{2} \mathrm{Cl}_{2}$ were due to the strong $\mathrm{O} \cdots \mathrm{H}$ interactions that resulted from $\mathrm{N}-\mathrm{H} \cdots \mathrm{O}$ hydrogen bonds. The contributions of these interactions to the total HS were both $28.0 \%$ in the two solvates because of similar hydrogen bonds. The moderate spikes with chicken wing-like features near $d_{\mathrm{e}}+d_{\mathrm{i}}$ $\approx 2.8 \AA$ in both solvates were due to $\mathrm{Cl} \cdots \mathrm{H}$ interactions. The contributions of these interactions to HS was higher in RBM/ $\mathrm{CH}_{2} \mathrm{Cl}_{2}(21.5 \%)$ than in $\mathrm{RBM} / \mathrm{DMSO}$ (9.1\%) because of the stronger $\mathrm{C}-\mathrm{H} \cdots \mathrm{Cl}$ interactions and the $\mathrm{CH}_{2} \mathrm{Cl}_{2}$ molecules in the crystal structure of $\mathrm{RBM} / \mathrm{CH}_{2} \mathrm{Cl}_{2}$. Other common and dominant interactions were $\mathrm{C} \cdots \mathrm{H}$ contacts with $\mathrm{HS}$ contributions of $19.2 \%$ in $\mathrm{RBM} / \mathrm{DMSO}$ and $18.5 \%$ in $\mathrm{RBM} / \mathrm{CH}_{2} \mathrm{Cl}_{2} \cdot \mathrm{H} \cdots \mathrm{H}$ interactions contributed more in RBM/DMSO (32.0\%) than in RBM/ $\mathrm{CH}_{2} \mathrm{Cl}_{2}(21.2 \%)$. The triangular region at the center of the FP of both solvates was ascribed to $\mathrm{C} \cdots \mathrm{C}$ contacts $(2.7 \%)$ (Fig. S5 $\dagger$ ). These contacts are a typical and characteristic indicator of significant $\pi \cdots \pi$ interactions and the $\pi$-system is represented by the $\mathrm{C}$ atoms of the aromatic rings. ${ }^{33}$

3.1.3. Morphological analysis. RBM/DMSO exhibited a transparent cuboid block structure with a smooth surface [Fig. 4(a)]. $\mathrm{RBM} / \mathrm{CH}_{2} \mathrm{Cl}_{2}$ presented a hexagonal plate structure

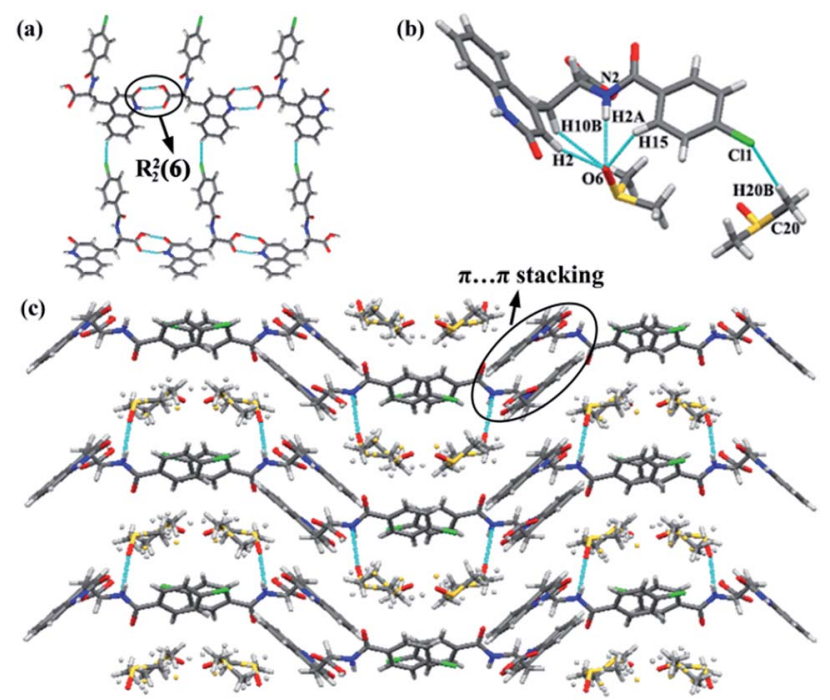

Fig. 1 (a) Hydrogen bond network of RBM/DMSO sustained by $\mathrm{R}_{2}^{2}(8)$ dimer motifs and weak $\mathrm{C}-\mathrm{H} \cdots \mathrm{Cl}$ hydrogen bonds. (b) Interactions between DMSO and RBM molecules. (c) View of the 2D packing of RBM/DMSO down the $c$-axis. DMSO molecules were located between the $\mathrm{W}$-shaped layers.
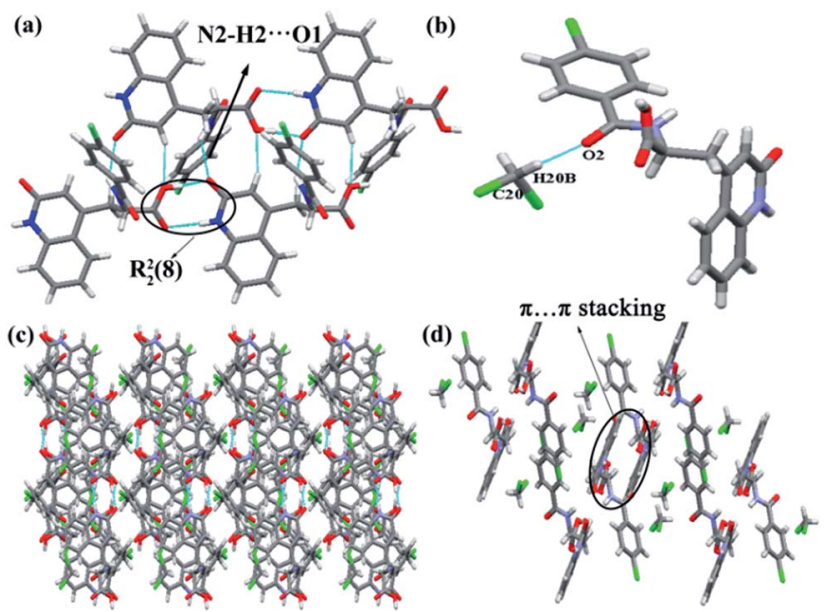

Fig. 2 (a) Hydrogen bond network of $\mathrm{RBM} / \mathrm{CH}_{2} \mathrm{Cl}_{2}$ sustained by $\mathrm{R}_{2}^{2}(8)$ dimer motifs, $\mathrm{N} 2-\mathrm{H} 2 \cdots \mathrm{O} 1$ hydrogen bonds, and the weak hydrogen bonds of $\mathrm{C} 2-\mathrm{H}_{2} \mathrm{~A} \cdots \mathrm{O}$. (b) Interactions between $\mathrm{CH}_{2} \mathrm{Cl}_{2}$ and RBM molecules. (c) Corrugated sheet viewed down the $\mathrm{c}$-axis. (d) $\pi \cdots \pi$ stacking in $\mathrm{RBM} / \mathrm{CH}_{2} \mathrm{Cl}_{2}$.

that immediately lost transparency in air [Fig. 4(b)]. Meanwhile, $\mathrm{RBM} / \mathrm{EtOH} / \mathrm{H}_{2} \mathrm{O}$ exhibited a transparent needle-like structure [Fig. 4(d)]. Although $\mathrm{RBM} / \mathrm{H}_{2} \mathrm{O}$ also displayed a needle-like structure, the needles were considerably smaller and were integrated as white spherules [Fig. 4(c)].

3.1.4. XRPD analysis. The experimental XRPD patterns of $\mathrm{RBM} / \mathrm{DMSO}$ and $\mathrm{RBM} / \mathrm{CH}_{2} \mathrm{Cl}_{2}$ matched well with the calculated patterns (Fig. S6 $\dagger$ ). The RBM solvates were readily distinguished from form 1 by the XRPD patterns and can be identified by the diagnostic peaks. The diagnostic peaks were at $6.10^{\circ}, 18.22^{\circ}$, and $19.88^{\circ}$ for RBM/DMSO; $9.32^{\circ}, 16.53^{\circ}$, and $26.79^{\circ}$ for RBM/ $\mathrm{CH}_{2} \mathrm{Cl}_{2} ; 11.17^{\circ}, 14.57^{\circ}$, and $25.58^{\circ}$ for $\mathrm{RBM} / \mathrm{H}_{2} \mathrm{O}$; and $7.98^{\circ}$ and $18.91^{\circ}$ for RBM/EtOH/ $\mathrm{H}_{2} \mathrm{O}$ [Fig. 5(a) and Tables S1-S4†]. The XRPD pattern of $\mathrm{RBM} / \mathrm{H}_{2} \mathrm{O}$ was consistent with that reported in a Chinese patent (Fig. S7 $\dagger$ ), which confirmed its monohydrate form. ${ }^{24}$

3.1.5. DSC and TGA analyses. The DSC and TGA curves of the RBM solvates are illustrated in Fig. 5(b) and 6, respectively. An endothermic peak was observed in the DSC curve of RBM/ DMSO at $100-150{ }^{\circ} \mathrm{C}$, which was ascribed to the removal of DMSO. Mass reduction at the same temperature range was $27.77 \%$, which was consistent with the theoretical DMSO content $(29.65 \%)$ based on lattice DMSO with $1: 2$ stoichiometry. $\mathrm{RBM} / \mathrm{CH}_{2} \mathrm{Cl}_{2}$ achieved a mass reduction of $12.55 \%$ during the first period, which was attributed to the removal of $\mathrm{CH}_{2} \mathrm{Cl}_{2}$ molecules. The experimental weight loss was lower than the theoretical weight loss (18.64\%), thus indicating that molecules were partially lost before the TGA test because of the very low boiling point of $\mathrm{CH}_{2} \mathrm{Cl}_{2}$. In the DSC curve, $\mathrm{RBM} / \mathrm{CH}_{2} \mathrm{Cl}_{2}$ exhibited a broad endothermic peak before $120{ }^{\circ} \mathrm{C}$ (removal of $\mathrm{CH}_{2} \mathrm{Cl}_{2}$ ) and further showed an exothermic phase transformation at $210-220{ }^{\circ} \mathrm{C}$. The DSC curve of $\mathrm{RBM} / \mathrm{H}_{2} \mathrm{O}$ showed a broad endothermic peak before $120^{\circ} \mathrm{C}$ and a small exothermic peak at $280-290{ }^{\circ} \mathrm{C}$, which were ascribed to dehydration and transition, respectively. The weight loss of $4.28 \%$ during the 

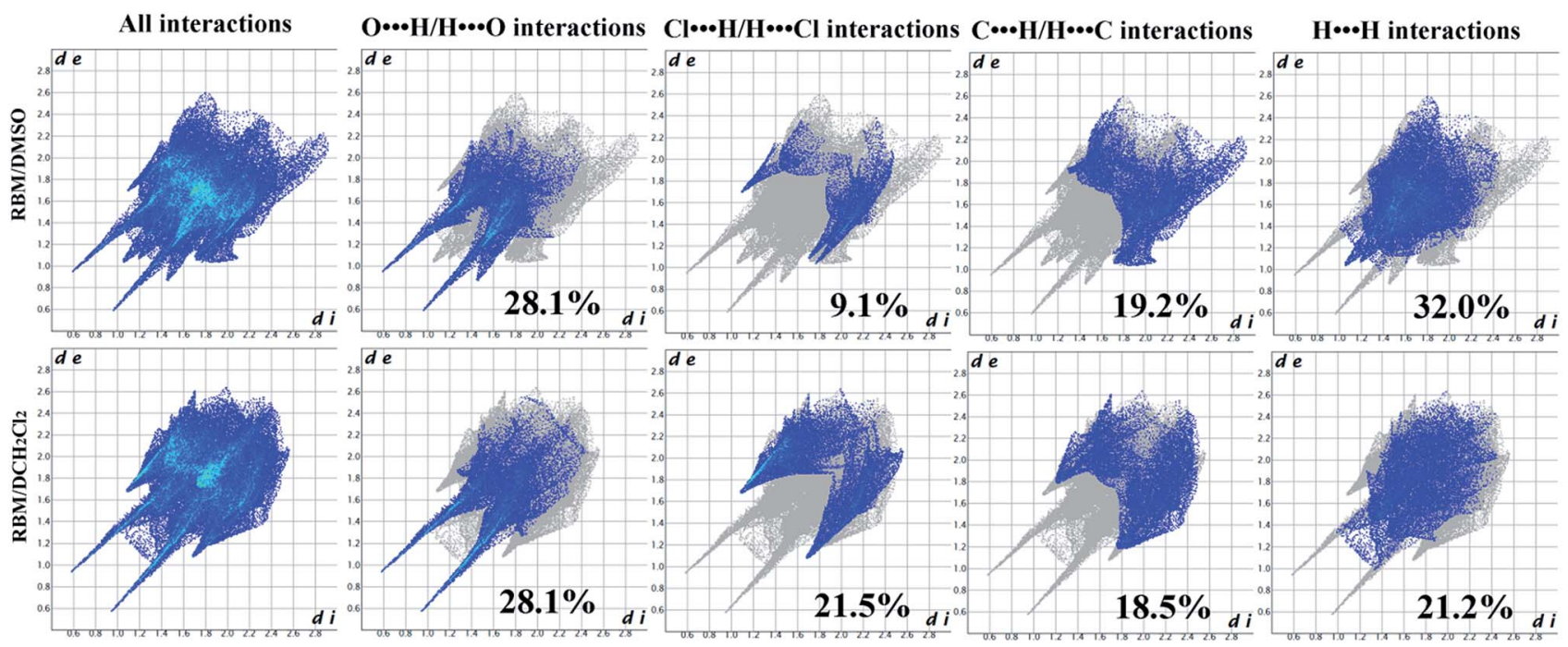

Fig. 3 2D FPs of RBM/DMSO and $\mathrm{RBM} / \mathrm{CH}_{2} \mathrm{Cl}_{2}$.

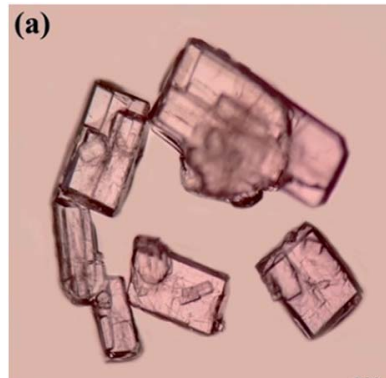

(b)
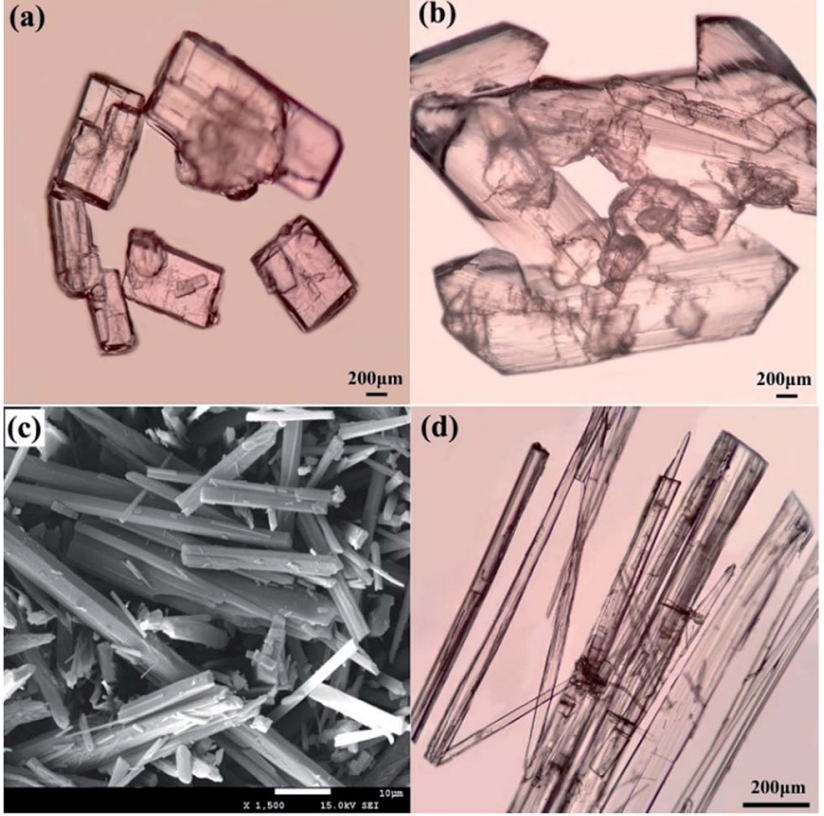

(d)

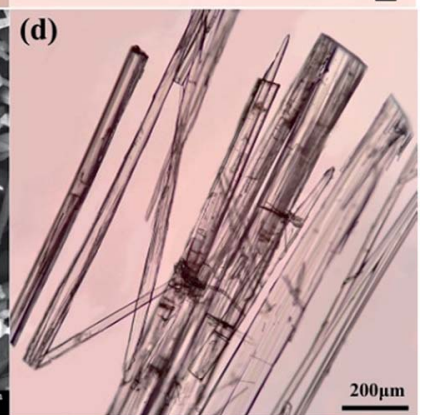

Fig. 4 Morphological images of RBM solvates: (a) RBM/DMSO, (b) $\mathrm{RBM} / \mathrm{CH}_{2} \mathrm{Cl}_{2}$, (c) $\mathrm{RBM} / \mathrm{H}_{2} \mathrm{O}$, and (d) RBM/EtOH/ $/ \mathrm{H}_{2} \mathrm{O}$.

first stage indicated that the stoichiometric ratio of RBM to water molecules was $1: 1\left[\Delta m_{\text {cal. }}\left(-\mathrm{H}_{2} \mathrm{O}\right)=4.63 \%\right] . \mathrm{RBM} / \mathrm{EtOH} /$ $\mathrm{H}_{2} \mathrm{O}$ showed two mass steps of $5.83 \%$ and $2.80 \%$ at $50-100{ }^{\circ} \mathrm{C}$ and $140-160{ }^{\circ} \mathrm{C}$, respectively. This phenomenon suggested the possible presence of $0.5 \mathrm{EtOH}\left[\Delta m_{\text {cal. }}(-0.5 \mathrm{EtOH})=5.85 \%\right]$ and $0.5 \mathrm{H}_{2} \mathrm{O}\left[\Delta m_{\text {cal. }}\left(-0.5 \mathrm{H}_{2} \mathrm{O}\right)=2.37 \%\right]$ molecules in the crystal structure of $\mathrm{RBM} / \mathrm{EtOH} / \mathrm{H}_{2} \mathrm{O}$. The two broad endothermic peaks before $200{ }^{\circ} \mathrm{C}$ in the DSC curve further confirmed the hemiethanol hemihydrate structure of $\mathrm{RBM} / \mathrm{EtOH} / \mathrm{H}_{2} \mathrm{O}$. Furthermore, these two peaks were attributed to the removal of EtOH and $\mathrm{H}_{2} \mathrm{O}$ molecules. The peak at approximately $300^{\circ} \mathrm{C}$ for each DSC curve was broad or split, indicating that the solid forms
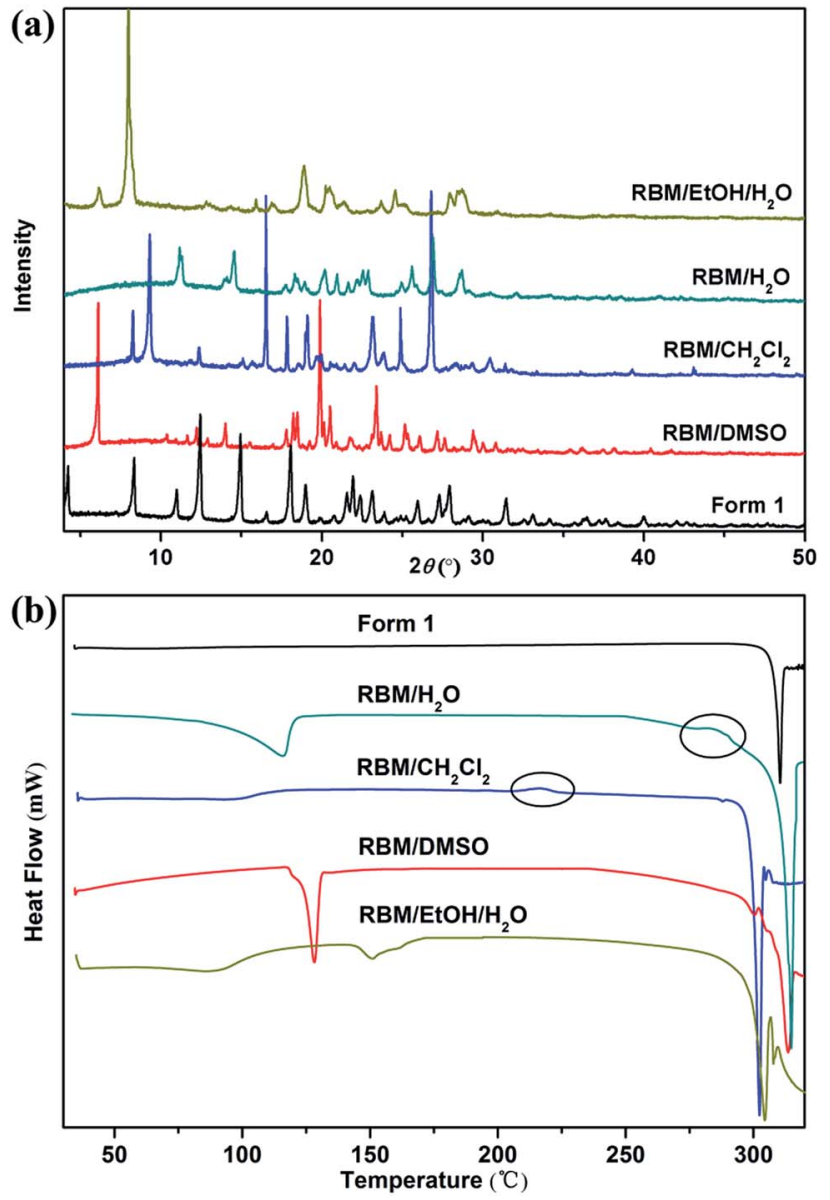

Fig. 5 (a) XRPD patterns and (b) DSC curves of the four solvates and form 1 of RBM.

obtained through desolvation or transformation melted with decomposition. This phenomenon was consistent with that indicated by the TGA results. 

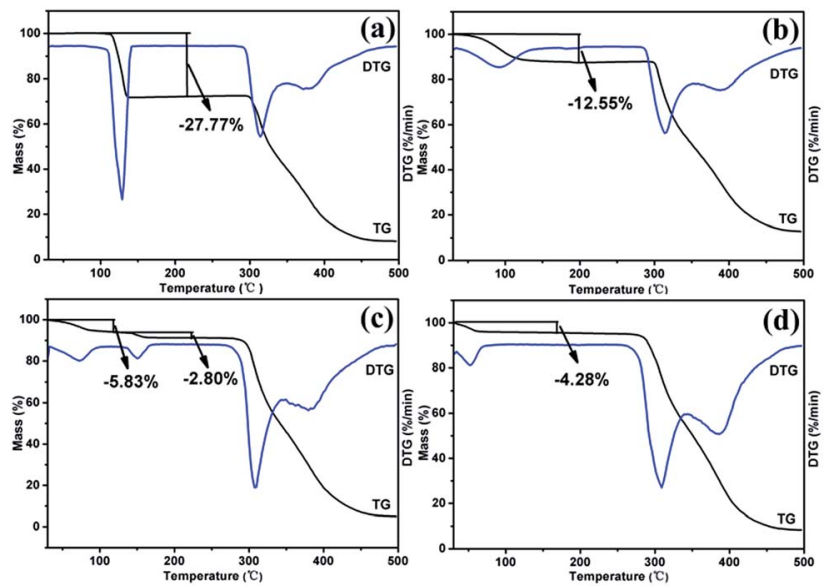

Fig. 6 TGA curves of the RBM solvates: (a) RBM/DMSO, (b) RBM/ $\mathrm{CH}_{2} \mathrm{Cl}_{2}$, (c) $\mathrm{RBM} / \mathrm{H}_{2} \mathrm{O}$, and (d) $\mathrm{RBM} / \mathrm{EtOH} / \mathrm{H}_{2} \mathrm{O}$.

\subsection{Phase transitions upon heating}

The modifications formed in solvates by solvent removal must be determined for screening novel solid forms. The phase transitions upon heating were investigated based on the thermal events displayed in the DSC curves.

$\mathrm{RBM} / \mathrm{DMSO}$ and $\mathrm{RBM} / \mathrm{EtOH} / \mathrm{H}_{2} \mathrm{O}$ transformed to form 1 after desolvation (Fig. S8 $\dagger$ ). The XRPD patterns detected at $150{ }^{\circ} \mathrm{C}$ and $220{ }^{\circ} \mathrm{C}$ for $\mathrm{RBM} / \mathrm{CH}_{2} \mathrm{Cl}_{2}$ were considerably different from those for $\mathrm{RBM} / \mathrm{CH}_{2} \mathrm{Cl}_{2}$ [Fig. 7(a)]. No weight loss was observed in the TGA curves before melting and decomposition, and no desolvation peak was detected in the DSC curves [Fig. 7(a) and (c)].
Moreover, the two XRPD patterns were different from that of forms 1 and 2 (Fig. S9†). ${ }^{23}$ Thus, two novel polymorphs (forms 3 and 4) were generated while heating $\mathrm{RBM} / \mathrm{CH}_{2} \mathrm{Cl}_{2}$. Together with the DSC result, form 3 was generated by the removal of $\mathrm{CH}_{2} \mathrm{Cl}_{2}$ $\left(150{ }^{\circ} \mathrm{C}\right)$ and was transformed to form 4 when further heated at $220^{\circ} \mathrm{C}$ [Fig. 7(d)]. A novel polymorph (form 5) was obtained after dehydration of $\mathrm{RBM} / \mathrm{H}_{2} \mathrm{O}$, as indicated by the XRPD, TGA, and DSC results at $150{ }^{\circ} \mathrm{C}$. The exothermic peak at $280-290{ }^{\circ} \mathrm{C}$ demonstrated that form 5 transformed into form 4 when heated at high temperature. In conclusion, three novel RBM polymorphs were obtained by the desolvation and transformation of the solvates. This phenomenon is significant for RBM development because the novel polymorphs may possess desirable physical and chemical properties.

\subsection{Accelerated stability tests}

Fig. 8 displays the XRPD patterns of the RBM solid forms, which were monitored at $40{ }^{\circ} \mathrm{C}$ and $75 \%$ RH. RBM/DMSO and RBM/ $\mathrm{EtOH} / \mathrm{H}_{2} \mathrm{O}$ were both converted to form 1 within three days [Fig. 8(a) and (d)]. $\mathrm{RBM} / \mathrm{CH}_{2} \mathrm{Cl}_{2}$ transformed to form 3, which could remain stable for three months at $40{ }^{\circ} \mathrm{C}$ and $75 \% \mathrm{RH}$ [Fig. 8(b)]. Both $\mathrm{RBM} / \mathrm{H}_{2} \mathrm{O}$ and form 4 showed relatively good stability because their XRPD patterns were nearly unchanged for three months [Fig. 8(c) and (e)]. Form 5 was unstable and could easily absorb water for reconversion to $\mathrm{RBM} / \mathrm{H}_{2} \mathrm{O}$ [Fig. 8(f)].

\subsection{Solubility and dissolution studies}

Considering stability and security, the apparent solubility and dissolution rate of $\mathrm{RBM} / \mathrm{H}_{2} \mathrm{O}$, form 3 , and form 4 were
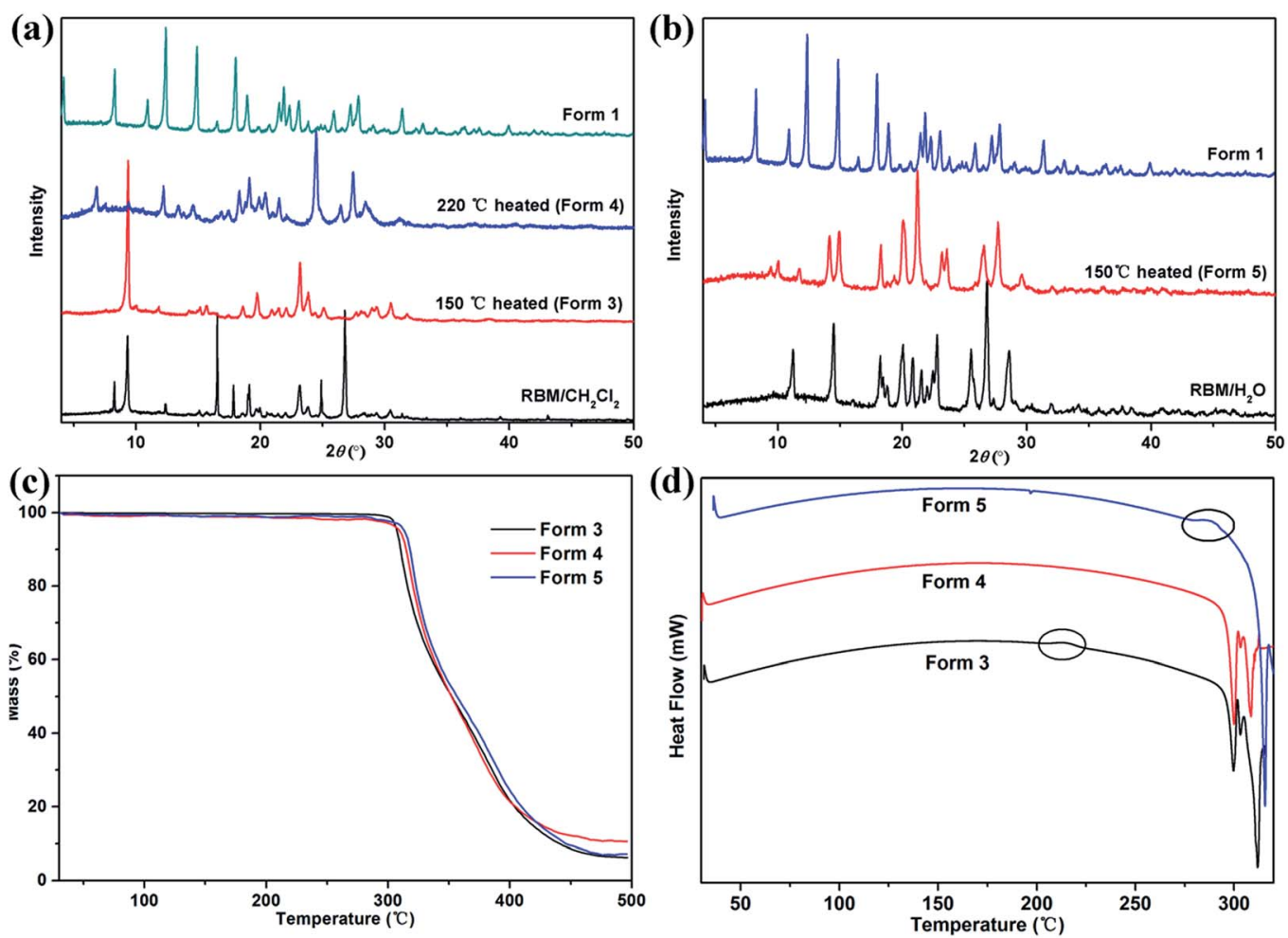

Fig. 7 XRPD patterns of (a) RBM/CH $\mathrm{Cl}_{2} \mathrm{Cl}_{2}$ heated at $150{ }^{\circ} \mathrm{C}$ and $220^{\circ} \mathrm{C}$, (b) RBM/ $\mathrm{H}_{2} \mathrm{O}$ heated at $150{ }^{\circ} \mathrm{C}$, (c) TGA, and (d) DSC curves of forms $3-5$. 

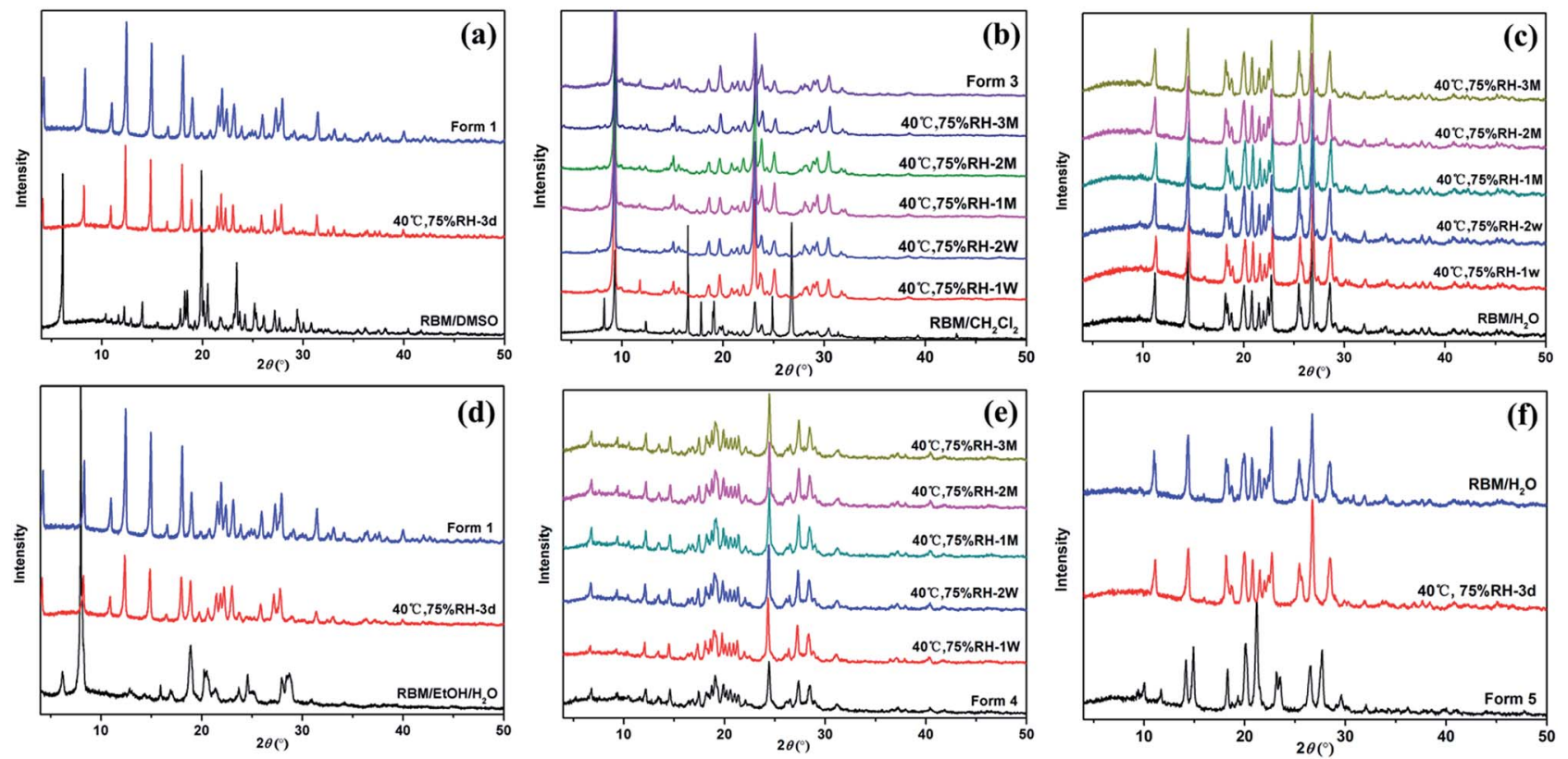

Fig. 8 Stability of (a) RBM/DMSO, (b) RBM/CH $\mathrm{C}_{2} \mathrm{Cl}_{2}$ and form 3, (c) RBM/ $\mathrm{H}_{2} \mathrm{O}$, (d) RBM/EtOH/ $\mathrm{H}_{2} \mathrm{O}$, (e) form 4, and (f) form 5 monitored with XRPD at $40{ }^{\circ} \mathrm{C}$ and $75 \% \mathrm{RH}$. (d = day, $\mathrm{W}=$ week, $\mathrm{M}=$ month).
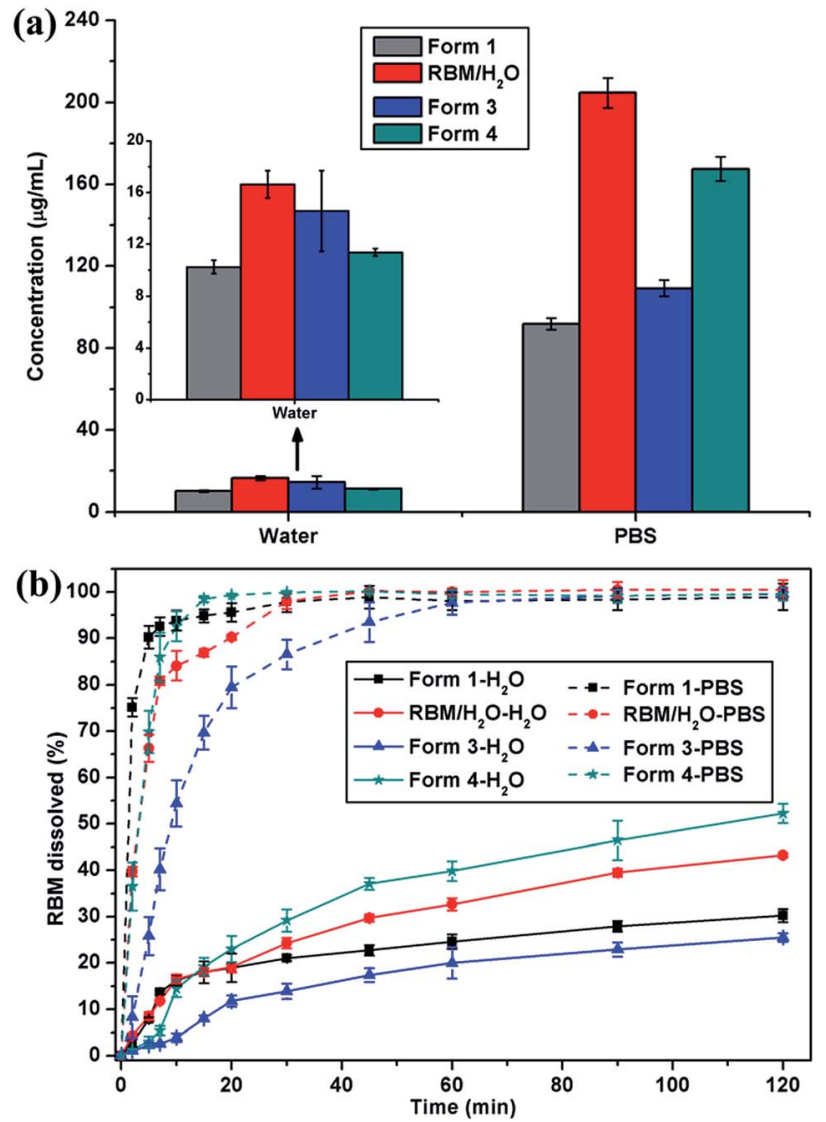

Fig. 9 (a) Solubility histograms and (b) dissolution profiles of form 1 , $\mathrm{RBM} / \mathrm{H}_{2} \mathrm{O}$, form 3, and form 4 in water and PBS (mean \pm standard deviation, $n=3$ ). investigated and compared with those of form $1 . \mathrm{RBM} / \mathrm{H}_{2} \mathrm{O}$, form 3 , and form 4 demonstrated higher solubility than form 1 in water and PBS [Fig. 9(a)]. Especially $\mathrm{RBM} / \mathrm{H}_{2} \mathrm{O}$, the solubility of which was 1.62 and 2.23 times higher than form 1 in water and PBS, respectively. The solid residues obtained by centrifugation and filtration after solubility determination were analyzed by XRPD (Fig. S10†). Although forms 3 and 4 were converted to form 1, the apparent solubility of the two forms remained higher than that of the original form 1 in water and PBS. No transformation occurred for $\mathrm{RBM} / \mathrm{H}_{2} \mathrm{O}$. Moreover, its solid residues showed increased crystallinity after solubility examination. Thus, $\mathrm{RBM} / \mathrm{H}_{2} \mathrm{O}$ is a potential substitute for form 1 in clinical treatment given its dominant solubility and good stability.

$\mathrm{RBM} / \mathrm{H}_{2} \mathrm{O}$ and form 4 showed a faster dissolution rate than form 1 after $20 \mathrm{~min}$ of dissolution in water; moreover, the cumulative drug release of the forms was considerably higher than that of form 1 after 120 min [Fig. 9(b)]. When dissolved in PBS, the three RBM solid forms exhibited a slower dissolution than form 1. However, their cumulative dissolution reached approximately $100 \%$ within $60 \mathrm{~min}$. $\mathrm{RBM} / \mathrm{H}_{2} \mathrm{O}$ and form 4 , in particular, almost completely dissolved after $30 \mathrm{~min}$. These results indicated that $\mathrm{RBM} / \mathrm{H}_{2} \mathrm{O}$ and form 4 had a comparative or even better solubility and dissolution characteristics than form 1. Thus, $\mathrm{RBM} / \mathrm{H}_{2} \mathrm{O}$ and form 4 may be developed as novel solid forms of RBM for clinical applications.

\section{Conclusions}

Four solvates and three novel polymorphs of RBM were obtained. The crystal structures of RBM/DMSO and $\mathrm{RBM} / \mathrm{CH}_{2} \mathrm{Cl}_{2}$ were determined via SXRD. Both structures were sustained by $\mathrm{R}_{2}^{2}(8)$ dimer motifs which formed through $\mathrm{O}-\mathrm{H} \cdots \mathrm{O}$ and $\mathrm{N}-\mathrm{H} \cdots \mathrm{O}$ 
hydrogen bonds. The main difference between the two forms

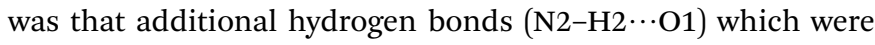
absent from RBM/DMSO, were present in $\mathrm{RBM} / \mathrm{CH}_{2} \mathrm{Cl}_{2}$. The $2 \mathrm{D}$ FP result indicated that the subtle intermolecular interactions of $\mathrm{RBM} / \mathrm{DMSO}$ and $\mathrm{RBM} / \mathrm{CH}_{2} \mathrm{Cl}_{2}$ were significantly different. The stability results at $40{ }^{\circ} \mathrm{C}$ and $75 \% \mathrm{RH}$ indicated that $\mathrm{RBM} /$ DMSO and $\mathrm{RBM} / \mathrm{EtOH} / \mathrm{H}_{2} \mathrm{O}$ transformed to form 1 and that form 5 was converted to $\mathrm{RBM} / \mathrm{H}_{2} \mathrm{O}$. $\mathrm{RBM} / \mathrm{H}_{2} \mathrm{O}$, form 3 , and form 4 showed good stability. In addition, $\mathrm{RBM} / \mathrm{H}_{2} \mathrm{O}$, form 3 , and form 4 displayed a higher solubility than form 1 in water and PBS. Furthermore, the dissolution rates of $\mathrm{RBM} / \mathrm{H}_{2} \mathrm{O}$ and form 4 in water were faster than that of form 1 . Thus, $\mathrm{RBM} / \mathrm{H}_{2} \mathrm{O}$ and form 4 exhibited potential to be developed as novel solid forms of RBM for clinical applications, which is meaningful for the drug development of RBM.

\section{Acknowledgements}

This work was supported by the Applied Basic Research Project of Sichuan Province (Grant No. 2014JY0042), the National Development and Reform Commission and Education of China (Grant No. 2014BW011), and the Large-scale Science Instrument Shareable Platform Construction of Sichuan Province (Grant No. 2015JCPT0005-15010102).

\section{References}

1 C. Näther, I. Jess, P. G. Jones, C. Taouss and N. Teschmit, Cryst. Growth Des., 2013, 13, 1676-1684.

2 R. Bobrovs, L. Seton and N. Dempster, CrystEngComm, 2015, 17, 5237-5251.

3 J. P. Brog, C. L. Chanez, A. Crochet and K. M. Fromm, RSC Adv., 2013, 3, 16905.

4 N. Gong, K. Hu, G. Jin, G. Du and Y. Lu, RSC Adv., 2016, 6, 38709-38715.

5 S. H. Thorat, M. V. Patwadkar, R. G. Gonnade and R. Vaidhyanathan, CrystEngComm, 2014, 16, 8638-8641.

6 K. Xu, S. Zheng, Y. Zhai, L. Guo, P. Tang, J. Yan, D. Wu and H. Li, Int. J. Pharm., 2015, 486, 185-194.

7 D. E. Braun, P. G. Karamertzanis, J. B. Arlin, A. J. Florence, V. Kahlenberg, D. A. Tocher, U. J. Griesser and S. L. Price, Cryst. Growth Des., 2011, 11, 210-220.

8 S. Datta and D. J. Grant, Nat. Rev. Drug Discovery, 2004, 3, 42-57.

9 D. Maddileti, B. Swapna and A. Nangia, Cryst. Growth Des., 2015, 15, 1745-1756.

10 C. Näther, I. Jess, L. Seyfarth, K. Bärwinkel and J. Senker, Cryst. Growth Des., 2015, 15, 366-373.

11 A. O. Surov, K. A. Solanko, A. D. Bond, A. Bauer-Brandl and G. L. Perlovich, CrystEngComm, 2015, 17, 4089-4097.

12 U. J. Griesser, in The importance of solvates, Polymorphism in the Pharmaceutical Industry, 2006, pp. 211-233.

13 B. N. Patel, N. Bhanubhai and C. N. Suhagia, Int. J. Pharm. Pharm. Sci., 2012, 4, 270-273.

14 N. Variankaval, A. S. Cote and M. F. Doherty, AIChE J., 2008, 54, 1682-1688.

15 W. Xu, N. Gong, S. Yang, N. Zhang, L. He, G. Du and Y. Lu, J. Pharm. Sci., 2015, 104, 1256-1262.
16 H. X. Ding, C. A. Leverett, R. E. Kyne, K. K. C. Liu, S. J. Fink, A. C. Flick and C. J. O'Donnell, Bioorg. Med. Chem., 2015, 23, 1895-1922.

17 X. Wang, N. Gong, S. Yang, G. Du and Y. Lu, J. Pharm. Sci., 2014, 103, 2696-2703.

18 Z. Yin, Z. Li, W. Z. Yang, J. He and J. P. Cheng, Struct. Chem., 2005, 16, 641-647.

19 P. W. Cains, in Polymorphism in pharmaceutical solids: classical methods of preparation of polymorphs and alternative solid forms, 2009, pp. 76-138.

20 R. Pradhan, T. H. Tran, J. Y. Choi, I. S. Choi, H. G. Choi, C. S. Yong and J. O. Kim, Arch. Pharmacal Res., 2014, 38, 522-533.

21 N. T. Tung, C. W. Park, T. O. Oh, J. Y. Kim, J. M. Ha, Y. S. Rhee and E. S. Park, J. Pharm. Pharmacol., 2011, 63, 1539-1547.

22 S. Koh, Y. Inoue, T. Sugmimoto, N. Maeda and K. Nishda, Cornea, 2013, 32, 1219-1223.

23 S. H. Jeon and Y. T. Sohn, Arch. Pharmacal Res., 2016, 39, 508-515.

$24 \mathrm{X}$. Zeng and C. Jia, Preparation of a rebamipide monohydrate crystal form for use in drugs for treating diseases related to gastric mucosa injury, China Patent, CN 104418802, March 18, 2015.

25 J. Holland, D. Gooding and A. Chorlton, Novel rebamipide complexes and cocrystals, U.S. Patent, 20140039005, February 6, 2014.

26 Y. Chi, C. Liu, T. Ren, X. Wang, Q. Yang, Z. Yang, Y. Yang, S. Yang, J. Gu and C. Hu, Cryst. Growth Des., 2016, 16, 3180-3189.

27 X. Xiong, K. Xu, S. Li, P. Tang, Y. Xiao and H. Li, Drug Dev. Ind. Pharm., 2017, 43, 283-292.

28 O. V. Dolomanov, L. J. Bourhis and R. J. Gildea, J. Appl. Crystallogr., 2009, 42, 339-341.

29 G. M. Sheldrick, Acta Crystallogr., Sect. C: Struct. Chem., 2015, 71, 3-8.

30 C. F. Macrae, P. R. Edgington, P. McCabe, E. Pidcock, G. P. Shields, R. Taylor, M. Towler and J. van de Streek, J. Appl. Crystallogr., 2006, 39, 453-457.

31 M. A. Spackman and P. G. Byrom, Chem. Phys. Lett., 1997, 267, 215-220.

32 M. A. Spackman and D. Jayatilaka, CrystEngComm, 2009, 11, 19-32.

33 J. Bojarska, A. Fruziński and W. Maniukiewicz, J. Mol. Struct., 2016, 1116, 22-29.

34 M. A. Spackman and J. J. McKinnon, CrystEngComm, 2002, 4, 378-392.

35 S. K. Wolff, D. J. Grimwood, J. J. McKinnon, M. J. Turner, D. Jayatilaka and M. A. Spackman, Crystal explorer, The University of Western Australia, 2012.

36 W. H. Organization, in World Health Organization Technical Report Series: Annex 2: Stability testing of active pharmaceutical ingredients and finished pharmaceutical products, 2009, pp. 87-130.

37 T. Lu and C. Chen, Measurement, 2007, 40, 591-599.

38 J. Bernstein, R. E. Davis, L. Shimoni and N. L. Chang, Angew. Chem., Int. Ed. Engl., 1995, 34, 1555-1573. 